\title{
Dietitian first gastroenterology clinic: an initiative to reduce wait lists and wait times for gastroenterology outpatients in a tertiary hospital service
}

\author{
Rumbidzai N Mutsekwa, ${ }^{1}$ Russell Canavan, ${ }^{2}$ Anthony Whitfield, ${ }^{2,3}$ \\ Alan Spencer, ${ }^{1}$ Rebecca L Angus ${ }^{\oplus 1,3}$
}

\begin{abstract}
${ }^{1}$ Gold Coast Hospital and Health Service, Nutrition and Food Service Department, Hospital Boulevard Southport, Southport, Queensland, Australia ${ }^{2}$ Gold Coast Hospital and Health Service, Gastroenterology Department, Hospital Boulevard Southport, Southport, Queensland, Australia ${ }^{3}$ Health Sciences, Griffith University, Southport, Queensland, Australia
\end{abstract}

\section{Correspondence to} Ms Rumbidzai N Mutsekwa, Gold Coast Hospital and Health Service, Nutrition and Food Service Department, Hospital Boulevard Southport, Southport QLD 4215, Australia; rumbidzai. mutsekwa@health.qld.gov.au

Received 26 July 2018 Revised 5 October 2018 Accepted 9 October 2018 Published Online First

2 November 2018

\section{Check for updates}

(C) Author(s) (or their employer(s)) 2019. No commercial re-use. See rights and permissions. Published by BMJ.

To cite: Mutsekwa RN, Canavan R, Whitfield A, et al. Frontline Gastroenterology 2019;10:229-235.

\section{ABSTRACT}

Objective The demand for outpatient gastroenterology medical specialist consultations is above what can be met within budgetary and staffing constraints. This study describes the establishment of a dietitian first gastroenterology clinic to address this issue, the patient journey and its impact on wait lists and wait times in a tertiary gastroenterology service.

Design A dietitian first gastroenterology clinic model was developed and a mixed-methods approach used to evaluate the impact of the service over a 21-month period.

Setting Gold Coast University Hospital, Queensland, Australia (a public tertiary hospital). Patients 658 patients were triaged to the clinic between June 2016 and March 2018.

Intervention A dietitian first gastroenterology clinic for low-risk gastroenterology patients.

Main outcome measures We examined demographic, referral, wait list, wait time and service activity data, patient satisfaction and patient journey.

Results At the time of audit, 399 new (67.9\% female) and 307 review patients had been seen. Wait times for eligible patients reduced from 280 to 66 days and the percentage of those in breach of their recommended wait times reduced from $95 \%$ to zero. The average time from referral to discharge was 117.8 days with an average of 2.4 occasions of service. 277 patients $(69.4 \%)$ had been discharged to the care of their general practitioner and 43 patients (10.7\%) had an expedited specialist medical review. Patient surveys indicated a high level of satisfaction.

Conclusion A dietitian first gastroenterology model of care helps improve patient flow, reduces wait times and may be useful elsewhere to address outpatient gastroenterology service pressures.

\section{BACKGROUND}

Worldwide, wait times for medical specialist appointments in publicly funded health systems continue to be a concern. ${ }^{1}$ The demand for medical specialist outpatient appointments is above what can be met within budgetary limits. ${ }^{2-6}$ In Australia, federal and state governments have set targets for patient waiting times based on urgency. Referrals are prioritised as category 1 (to be seen within 30 days), category 2 (90 days) or category 3 (365 days). ${ }^{6}$ However, many patients wait longer than clinically recommended. ${ }^{56}$

Models of care where allied health practitioners are primary contact clinicians have been effective in improving patient access across a range of specialities and may release medical specialists to see more complex patients. ${ }^{7-10}$ Other benefits have included high patient and clinician satisfaction levels, cost-effectiveness and more efficient use of healthcare resources. $^{8}$ Dietitians are well placed to operate under extended scope models of care within gastroenterology outpatient services, as a significant proportion of patients referred have functional gut disorders which may be managed with lifestyle and dietary modification. ${ }^{11} 12$ The activities of an extended scope gastroenterology dietitian clinic have been previously reported ${ }^{13}$; however, there are limited studies on the impact of such on medical specialist wait lists and patient wait times. 
The aim of this study was to outline a model for the establishment of a dietitian first gastroenterology clinic (DFGC) in an outpatient department of a large tertiary hospital, to describe the characteristics of patients seen and to evaluate the impact of the clinic on gastroenterology wait lists, wait times, patient journeys and patient satisfaction levels.

\section{Description of the DFGC}

A proposal to establish a DFGC was developed and approved after wide stakeholder consultation as one of several strategies to reduce long wait lists for gastroenterology outpatient services. The project was allocated temporary funding for a 0.4 full-time equivalent (FTE) senior gastroenterology dietitian and a 0.2 FTE administration officer to support three half-day outpatient clinics per week. The dietitian was the primary contact for gastroenterology patients who were deemed eligible for the model of care.

Eligibility criteria and referral pathways were developed in alignment with the Queensland Gastroenterology Clinical Prioritisation Criteria 2016 (CPC), a clinical decision support tool developed to ensure appropriate triaging of referrals to public specialist outpatient services in a safe, consistent and equitable manner. ${ }^{14} \mathrm{~A}$ gastroenterology consultant triaged all referrals received from general practitioners (GPs). DFGC criteria included category 2 patients, $<50$ years old, referred with altered bowel motions, abdominal pain, constipation, diarrhoea, dyspepsia/heartburn/ reflux and/or non-CPC complaints (nausea or abdominal bloating). Patients were excluded where the GP letter highlighted 'red flags' including weight loss ( $\geq 5 \%$ of body weight in previous 6 months), iron deficiency in men and postmenopausal women, unexplained iron deficiency in premenopausal women, abnormal imaging, persistent abdominal pain, gastrointestinal bleeding, nocturnal diarrhoea, persistent vomiting, dysphagia, history of polyps and/or personal or family history of Barrett's oesophagus, gastrointestinal cancers or inflammatory bowel disease. Administration officers used transcripts to explain the service and offer patients appointments in the DFGC. A service description sheet was mailed to the patient with their appointment letter. The DFGC was an opt-out service. Patients were advised that they could choose to remain on the medical specialist wait list if they preferred.

Following triage, patients were assessed and managed in the DFGC. Dietitians were trained to screen for organic disease using a structured process which included medical/family history, exclusion of red flags not included in referral information, blood or stool tests. Dietitians were credentialled to appropriately request pathology (full blood count, electrolytes and liver function tests, iron studies, coeliac serology, thyroid function tests, vitamin $\mathrm{B}_{12}$, folate, faecal occult blood test, calprotectin, stool microscopy and culture, faecal elastase, Helicobacter pylori,
$\mathrm{C}$ reactive protein and erythrocyte sedimentation rate) as part of extended scope practice for allied health. ${ }^{15}$ Patients assessed as requiring medical review were sent for expedited examination in a dedicated gastroenterology consultant clinic. Dietitians provided diet and lifestyle-related management strategies with patients discharged back to the care of their GP on satisfactory resolution of symptoms. Figure 1 shows the gastroenterology patient pathways after implementation of the DFGC.

\section{METHODS}

The study was undertaken in the gastroenterology outpatient department of a large tertiary hospital in Queensland, Australia.

An audit of the gastroenterology wait lists was conducted in April 2016, and patients meeting DFGC eligibility criteria were identified. The time from referral to first appointment (wait time) and time in breach of clinically recommended wait times were calculated. In April 2018, health service records were used to identify all patients seen in the DFGC since inception (22 June 2016 to 30 March 2018). The number of referrals to the gastroenterology service, number of referrals to the DFGC, new and review appointments, and occasions of service per patient were captured. Time from referral to first appointment (wait time), time in breach of clinically recommended wait times, referral to discharge (outpatient hospital episode) and first appointment to discharge (treatment time) were calculated. Patient demographic data including age, gender and reasons for referral were collated from medical records. Data were analysed in Microsoft Excel 2010 and IBM SPSS Statistics V.24. Pearson's $\chi^{2}$ test (or Fisher's exact test as required) was used to test association between referral reason and gender. Independent t-tests were used to test if the mean age was different between patients with and without each referral reason. Level of significance was set at $\mathrm{p}$ value $<0.05$.

Self-reported patient satisfaction was collected by anonymous survey offered to all patients seen in the first 4 months of DFGC operation. Survey forms were provided at the completion of clinic appointments and collected via a box in the waiting room, out of sight of the clinician to reduce social desirability bias. Patients rated their satisfaction on a visual analogue scale with a range of scores between 0 (minimum satisfaction) and $100 \mathrm{~mm}$ (maximum satisfaction). For reporting purposes, the scale was stratified into three categories: less than satisfied $<50 \mathrm{~mm}$, satisfied $50-79 \mathrm{~mm}$ and very satisfied $80-100 \mathrm{~mm}$. The survey also included openended questions which were analysed using Braun and Clarke's framework for thematic analysis. ${ }^{16}$ This process included initial familiarisation with the survey data, generation of a list of items that had recurring patterns, identification, review and definition of identified themes which were then provided as a summary. 


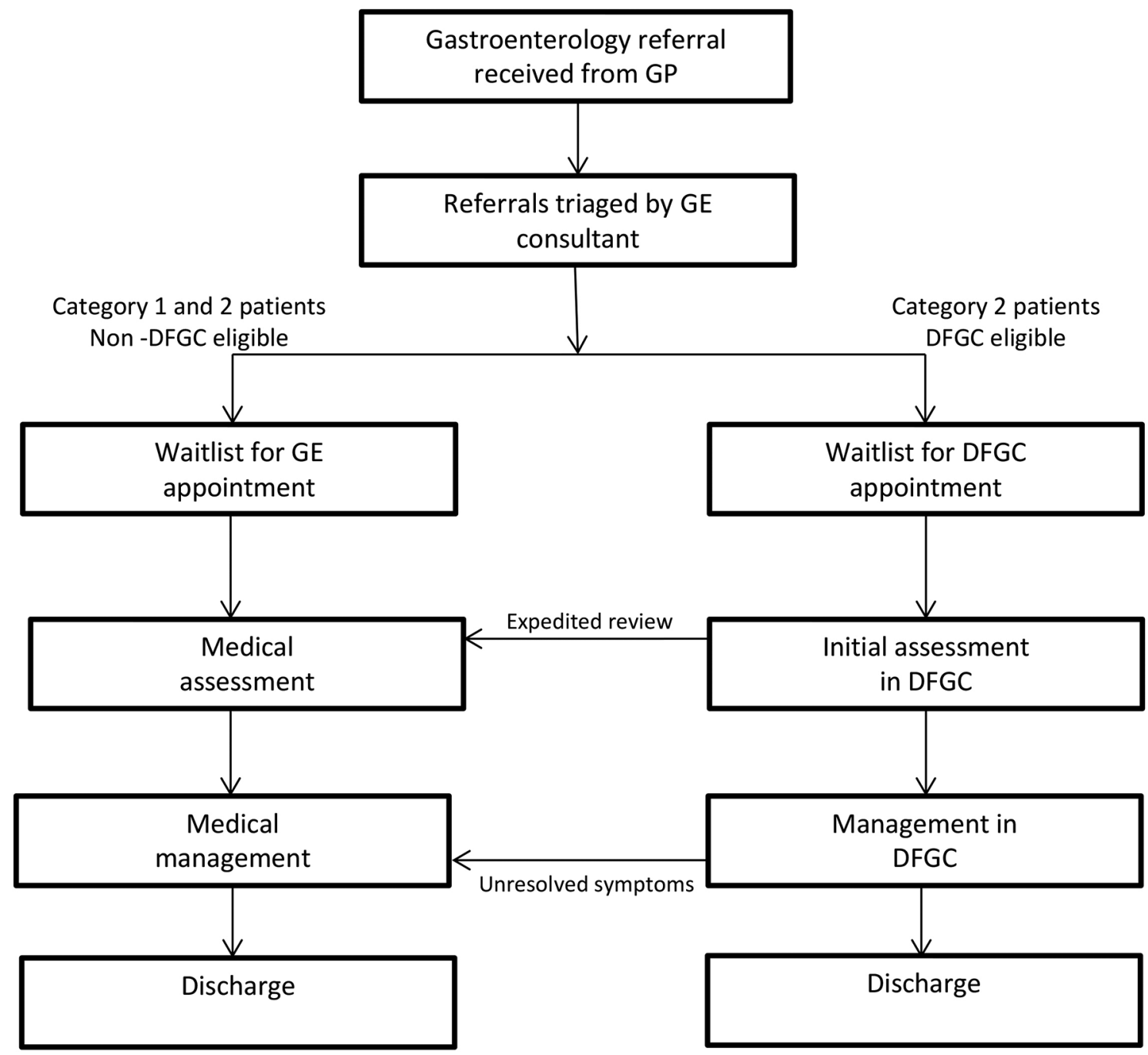

Figure 1 Flow diagram showing gastroenterology and dietitian first gastroenterology clinic (DFGC) pathways.

\section{RESULTS}

Wait list and wait times pre-DFGC and post-DFGC implementation

In April 2016, the audit of 619 patients on the gastroenterology wait list identified 124 category 1 , 414 category 2, 18 category 3 and 63 uncategorised patients. Of these, $10.2 \%(n=63)$ were deemed eligible for the DFGC. Moreover, 95\% $(n=60)$ of DFGC-eligible patients were in breach of their clinically recommended wait times (average wait time 280, SD 148, range 30-700 days). After 21 months of DFGC operation, the average wait times for DFGC-eligible patients had reduced to 66 days, and the number of these patients in breach of clinically recommended wait times reduced from 95\% (average breach days $=201$ ) to zero.

\section{Dietitian first gastroenterology clinic activity}

Between 22 June 2016 and 30 March 2018, 658 patients met the inclusion criteria and were triaged to the DFGC by the gastroenterology consultant. This represented $5.4 \%$ of all gastroenterology referrals received during the study period. There was a
$20 \%$ annual increase in referrals to the gastroenterology outpatient services during this time. Moreover, 399 of the DFGC-eligible patients attended an initial appointment, and there were an additional 307 review appointments during the study period. One hundred forty-seven patients were removed from the gastroenterology wait lists after failing to respond to appointment offers. The remainder had future appointments booked $(n=47)$ or were on the DFGC wait list $(n=65)$. Of 399 patients (15-50 years) seen in the DFGC, 277 (69.4\%) had been discharged without requiring specialist medical gastroenterology input. Forty-three $(10.7 \%)$ patients were triaged back to the gastroenterologist for review after 'red flags' not initially highlighted on the referral letter were identified. Two of these patients were found to have significant pathology following gastroenterologist assessment and further investigations. The average time for the DFGC gastroenterology outpatient hospital episode was 117.8 days (SD 75, range 11-370 days) and the treatment time was 52.7 days (SD 74, range 1-213 days). Patients had 2.4 occasions of service on average (SD 1.11, range $1-7)$. 
Table 1 Patient demographics by referral reason from general practitioner referral letter

\begin{tabular}{lccl}
\hline & $\begin{array}{l}\text { Number of } \\
\text { patients } \\
\text { (\% patients } \\
\text { with referral } \\
\text { reason) }\end{array}$ & $\begin{array}{l}\text { Number of } \\
\text { women } \\
\text { (\% women } \\
\text { in referral } \\
\text { group) }\end{array}$ & $\begin{array}{l}\text { Mean age } \\
( \pm \text { SD) years }\end{array}$ \\
\hline Referral reason & $399(100)$ & $271(67.9)$ & $32.0(8.6)$ \\
\hline Primary contact & $85(21.0)$ & $60(70.6)$ & $31.2(8.4)$ \\
\hline Total patients & $32(7.8)$ & $31(96.9)^{*}$ & $30.8(7.5)$ \\
\hline Diarrhoea & $64(16)$ & $44(68.8)$ & $33.7(8.6)$ \\
\hline Constipation & $186(47.4)$ & $143(76.9)^{*}$ & $30.5(8.3)^{*}$ \\
\hline Altered bowel habits & $86(21.6)$ & $41(47.7)^{*}$ & $34.3(8.7)^{*}$ \\
\hline $\begin{array}{l}\text { Abdominal pain } \\
\text { Dyspepsia/heartburn }\end{array}$ & $67(16.8)$ & $52(77.6)$ & $32.4(8.5)$ \\
\hline reflux & $27(6.8)$ & $26(96.3)^{*}$ & $29.1(8.2)$ \\
\hline Bloating & Nausea & & \\
\hline
\end{tabular}

Some patients were referred with more than one condition. Bloating and nausea are non-Clinical Prioritisation Criteria referral conditions.

* Significant differences between gender or mean age of patients with a given referral reason and those without, with $\mathrm{p}$ value $<0.01$.

\section{Reasons for referral}

Table 1 provides an overview of patient demographics and reason for referral as indicated by the GP referral letter. Sixty-nine per cent of patients had a single reason for referral, 24\% had two and 7\% had more than two. Referral with dyspepsia/heartburn/reflux was significantly more common in men, while referral with constipation, abdominal pain and nausea was significantly more common in women. People referred with abdominal pain were significantly younger than those without. People referred with dyspepsia/heartburn/ reflux were significantly older than those without.

\section{Patient satisfaction}

The patient satisfaction survey response rate was $83 \%$ (73 of 88 DFGC patients attending in June-October 2016). Patients reported high levels of satisfaction with the DFGC service across all domains and independent statements (table 2).

Thematic analysis identified four main discourses among the free-text responses (table 3). These were high levels of general satisfaction with the service, positive comments about clinician traits (including knowledge, skill, understanding and rapport), a sense of gratitude for the service and mixed comments about the wait times.

\section{DISCUSSION}

There is increasing pressure to provide timely access to medical care with limited healthcare funding. Allied health professionals working effectively in extended scope of practice roles are well placed to ease the burden of ever-growing wait lists and the increasing number of patients unable to be seen within clinically recommended times. ${ }^{9} 10$ This study demonstrates that a significant proportion of patients referred to
Table 2 Patient satisfaction scores with the dietitian first gastroenterology clinic

\begin{tabular}{|c|c|c|c|c|}
\hline \multirow{4}{*}{$\begin{array}{l}\text { Domain } \\
\text { Overall satisfaction }\end{array}$} & \multirow{4}{*}{$\begin{array}{l}\text { Mean } \\
\text { score } \\
\text { mm } \\
96.6\end{array}$} & \multirow{4}{*}{$\frac{S D}{0.81}$} & \multicolumn{2}{|c|}{$\begin{array}{l}\text { Patient satisfaction } \\
\mathrm{n}(\%)\end{array}$} \\
\hline & & & $\begin{array}{l}\text { Less than } \\
\text { satisfied }\end{array}$ & 0 \\
\hline & & & Satisfied & $1(1.4)$ \\
\hline & & & Very satisfied & $72(98.6)$ \\
\hline \multirow[t]{3}{*}{$\begin{array}{l}\text { Patient confidence in the } \\
\text { treating clinician }\end{array}$} & \multirow[t]{3}{*}{93.1} & \multirow[t]{3}{*}{1.74} & $\begin{array}{l}\text { Less than } \\
\text { confident }\end{array}$ & $2(2.7)$ \\
\hline & & & Confident & $2(2.7)$ \\
\hline & & & $\begin{array}{l}\text { Very } \\
\text { confident }\end{array}$ & $69(94.6)$ \\
\hline \multirow{3}{*}{$\begin{array}{l}\text { Patient confidence in } \\
\text { self-management after } \\
\text { appointments }\end{array}$} & \multirow[t]{3}{*}{86.5} & \multirow[t]{3}{*}{2.07} & $\begin{array}{l}\text { Less than } \\
\text { confident }\end{array}$ & $3(4.1)$ \\
\hline & & & Confident & $4(5.5)$ \\
\hline & & & $\begin{array}{l}\text { Very } \\
\text { confident }\end{array}$ & $66(90.4)$ \\
\hline \multirow[t]{3}{*}{$\begin{array}{l}\text { Extent to which patient } \\
\text { expectations were met }\end{array}$} & \multirow[t]{3}{*}{95.9} & \multirow[t]{3}{*}{0.91} & $\begin{array}{l}\text { Less than } \\
\text { satisfied }\end{array}$ & 0 \\
\hline & & & Satisfied & $2(2.7)$ \\
\hline & & & Very satisfied & $71(97.3)$ \\
\hline \multirow{3}{*}{$\begin{array}{l}\text { Likelihood that patient } \\
\text { would recommend service } \\
\text { to others }\end{array}$} & \multirow[t]{3}{*}{97.0} & \multirow[t]{3}{*}{0.78} & Less likely & 0 \\
\hline & & & Likely & $2(2.7)$ \\
\hline & & & Very likely & $71(97.3)$ \\
\hline \multirow{3}{*}{$\begin{array}{l}\text { Likelihood that patient } \\
\text { would attend future } \\
\text { scheduled appointments }\end{array}$} & \multirow[t]{3}{*}{97.7} & \multirow[t]{3}{*}{0.56} & Less likely & 0 \\
\hline & & & Likely & $1(1.4)$ \\
\hline & & & Very likely & 72 (98.6) \\
\hline
\end{tabular}

gastroenterology services are suitable for assessment, diagnosis and management in a DFGC. During the study period, over $5 \%$ of all gastroenterology referrals were triaged to the DFGC, increasing the capacity for medical specialists to see more urgent and complex cases. A limitation of this study was the simultaneous implementation of a number of initiatives within the health service to improve gastroenterology outpatient services. Consequently, we restricted our wait-list analyses to DFGC-eligible patients, as wait times for other patients were likely to be confounded by impacts from other programmes.

Dietitians are well placed to provide specialist dietetic input to gastroenterology patients with previous studies indicating that up 33\% of patients would benefit from dietetic input. ${ }^{17}$ Patients with functional gut disorders, a group expected to be among those captured by the DFGC eligibility criteria, are high users of healthcare as they may re-present to services having not achieved resolution of symptoms after previous medical consultations. ${ }^{18}$ Most patients who receive dietetic care for these conditions report satisfactory control of symptoms and improved quality of life. ${ }^{19}$ In line with a previous study, ${ }^{13}$ majority of patients seen were managed exclusively within the DFGC and discharged back to their GPs with satisfactory resolution of symptoms. It is also essential that 
Table 3 Themes arising from free-text responses to patient satisfaction surveys

\begin{tabular}{ll}
\hline Theme & Example responses \\
\hline $\begin{array}{l}\text { General } \\
\text { satisfaction with }\end{array}$ & Very impressed and excited about having more \\
the service & knowledge about my nutrition. \\
& Was a lot more positive than I was expecting. \\
& Was good going through different types of treatment \\
& paths instead of straight to surgery. Answered all my \\
& questions. \\
& I am 100\% happy with this service. \\
Positive clinician & Very happy with level of care and depth of \\
traits & understanding of my condition. \\
& (Dietitian) is lovely, which made it a much more \\
& pleasant appointment. \\
& Very friendly and informative. \\
& Very interesting suggestions and very clearly explained. \\
& Great service. Good listeners and professional-highly \\
& recommended. \\
I'm very grateful for this service. \\
Never thought one day I will get a chance to resolve this \\
problem. \\
gratitude
\end{tabular}

strategies continue to include effective diagnostic and management pathways for patients within the primary care setting to further help reduce wait lists.

Our results indicate that the reallocation of eligible patients directly from the general gastroenterology wait list to the DFGC wait list can result in reduced wait times for these patients, allowing assessment within clinically recommended time frames even within the context of increasing overall service demand. This is of clinical significance as long wait times contribute to the delay between diagnosis and treatment, which may impact on treatment outcomes for patients with serious pathology. ${ }^{20}$ Other patients will be anxious about their health for longer than necessary, and long waits may result in decreased quality of life and increased healthcare use including unnecessary investigations. ${ }^{2021}$ Long wait lists are often associated with patient frustration. ${ }^{1} 1022$ The current study indicates that a DFGC can provide timely assessment and management of eligible gastroenterology patients with very high levels of patient satisfaction. Here, surveys were conducted in the first 4 months of service operation when a backlog of patients from the existing long wait lists was being cleared. It is likely that the two patients who commented on lengthy waits had been on the gastroenterology referral list for extended periods (up to 2 years) before being seen in the DFGC. In addition to patient satisfaction, thorough evaluation of new models of care also requires investigation of patient health outcomes and this should be a focus of future work.

This study, which describes the DFGC patient journey from referral to discharge, may provide important information for use in health systems and workforce planning. While it was out of the scope of this study to compare the complete patient journeys for the traditional medical model of care and the DFGC, it was evident that eligible patients had previously been waiting longer for an initial specialist appointment than the time taken to complete the entire outpatient episode of care, from GP referral to discharge, through the DFGC. Gastrointestinal disorders have a substantial economic cost to the health system. ${ }^{23}$ The burden on the patient from potential lost work time and the effect on quality of life should also be considered in determining the economic value of timely treatment. Differences in medical specialist and allied health salaries, along with reduced procedural costs (gastroscopies and colonoscopies), suggest that the DFGC model may provide cost efficiencies over the traditional, medical specialist models. A comprehensive economic analysis is required to establish whether this is the case, and if so, what savings may be realised from the implementation of this model of care.

Benchmarking has indicated that implementation, level of activity and longevity of DFGCs across sites varies substantially. Previous studies have identified barriers and enablers in the implementation of extended scope of practice roles. ${ }^{8}{ }^{24}$ Strong multidisciplinary relationships, good communication, support from medical stakeholders, management support, appropriate resource allocation (including administrative support) and dedicated clinic spaces have been integral in the successful establishment and maintenance of the DFGC within our health service. Strong clinical governance frameworks with appropriate risk management strategies such as development of clear clinical pathways, scheduled clinical supervision with the consultant gastroenterologist, opportunity to discuss complex cases and pathways to expedite medical specialist review when required has also contributed to successful implementation while ensuring quality and safe patient care.

Multiple dietitians within the health service were provided with competency-based training for work within the DFGC to ensure that service continuity was not dependent on the employment of individuals. In future, formalised education and training for these specialised roles may assist in providing standardisation of care, safety for patients, protection for practitioners and sustainability for the model of care. ${ }^{910}$ The potential exists to further extend the role of specialist dietitians into triaging to further reduce pressures on medical specialists. The authors also note the importance of setting realistic time frames for the establishment and evaluation of such services to allow adequate 
time to demonstrate success and/or highlight areas for improvement.

\section{CONCLUSION}

This study indicates that incorporation of a dietitian-first clinic within a gastroenterology service can assist in timely patient assessment and care, and contributes to the growing body of evidence for models of care that use allied health staff acting in an extended scope of practice. With appropriate adaptation and attention to the discussed enablers, this model of care could provide similar benefits in other settings. Future research should investigate health-related patient outcomes, and robust economic analysis is imperative to provide evidence for the cost-effectiveness of such models of care.

\section{Significance of this study}

\section{What is already known on this topic}

- There is increasing demand for gastroenterology specialist services putting pressure on public hospital resources.

- Models of care using allied health practitioner-led models working in an extended scope of practice and as primary contact clinicians have proven effective in managing wait-list demand in a range of specialities.

- Dietitians are well placed to operate under these models of care to help address wait-list pressures in gastroenterology services.

\section{What this study adds}

- This study provides a model for establishment of a dietitian first gastroenterology clinic along with enablers for successful implementation.

- This study evaluates the patient journey and impact of this model of care on wait times.

\section{How might it impact on clinical practice in the foreseeable future \\ - Dietitian first gastroenterology models of care can be considered by health services administrators, gastroenterology medical specialists and allied health leaders as an effective strategy to address outpatient gastroenterology demands and optimise access to dietetic services.}

Acknowledgements The authors acknowledge the Gold Coast Hospital and Health Service for funding this model of care and recognise the contribution of the steering committee. We thank the staff of the GCHHS gastroenterology, nutrition and data management departments, other health services that provided benchmarking data and the patients involved in this study.

Contributors AS, RC and RNM devised the project, the main conceptual ideas and proof outline. RNM and RLA reviewed the literature. RNM and AW extracted the data. RLA and RNM analysed and interpreted the data. RNM and RLA drafted the manuscript. All authors provided critical feedback and helped shape the research, analysis, interpretation of results and revision of manuscript and have read and approved the final manuscript.
Funding The authors have not declared a specific grant for this research from any funding agency in the public, commercial or not-for-profit sectors.

Competing interests None declared.

Patient consent Not required.

Ethics approval Gold Coast Hospital and Health Service Ethics Comittee (reference: HREC/17/QGC/191).

Provenance and peer review Not commissioned; externally peer reviewed.

Data sharing statement Due to our institutional restrictions, there are no data that can be shared. However, further information can be obtained from the corresponding author.

\section{REFERENCES}

1 Siciliani L, Hurst J. Tackling excessive waiting times for elective surgery: a comparative analysis of policies in $12 \mathrm{OECD}$ countries. Health Policy 2005;72:201-15.

2 Duckett SJ. Health workforce design for the 21st century. Aust Health Rev 2005;29:201-10.

3 Segal L, Bolton T. Issues facing the future health care workforce: the importance of demand modelling. Aust New Zealand Health Policy 2009;6:12.

4 Health Workforce Australia. National Health Workforce Innovation and Reform Strategic Framework for Action 20112015. Adelaide, South Australia: Health Workforce Australia, 2011.

5 Allied Health Professions' Office of Queensland. Ministerial taskforce on health practitioner expanded scope of practice: final report. Brisbane: Queensland Government, 2014.

6 Queensland Government, 2015. Hospital care, surgical procedures and waiting lists. https://www.qld.gov.au/health/ services/hospital-care/waiting-lists (accessed 24 May 2018).

7 Health Workforce Australia. Health Workforce Australia 2011: National Health Workforce Innovation and Reform Strategic Framework for Action 2011-2015, 2011.

8 Stute M, Moretto N, Raymer M, et al. Process to establish 11 primary contact allied health pathways in a public health service. Aust Health Rev 2018;42:258-65.

9 McPherson K, Kersten P, George S, et al. A systematic review of evidence about extended roles for allied health professionals. J Health Serv Res Policy 2006;11:240-7.

10 Saxon RL, Gray MA, Oprescu FI. Extended roles for allied health professionals: an updated systematic review of the evidence. J Multidiscip Healthc 2014;7:479-88.

11 Williams M, Barclay Y, Benneyworth R, et al. Using best practice to create a pathway to improve management of irritable bowel syndrome: aiming for timely diagnosis, effective treatment and equitable care. Frontline Gastroenterol 2016;7:323-30.

12 Shivaji UN, Ford AC. Prevalence of functional gastrointestinal disorders among consecutive new patient referrals to a gastroenterology clinic. Frontline Gastroenterol 2014;5:266-71.

13 Ryan D, Pelly F, Purcell E. The activities of a dietitian-led gastroenterology clinic using extended scope of practice. BMC Health Serv Res 2016;16:604.

14 Queenland Health Clinical Excellence Division, 2016. Clinical prioritisation criteria: Gastroenterology. https://cpc.health.qld. gov.au/Specialty/7/gastroenterology (accessed 6 Jun 2018).

15 Allied Health Professions' Office of Queensland. Guideline for allied health professionals requesting pathology tests: Queensland Government, 2015.

16 Braun V, Clarke V. Using thematic analysis in psychology. Qual Res Psychol 2006;3:77-101.

17 Lomer MCE. The role of a consultant dietitian in gastroenterology in the United Kingdom. Nutr Today $2009 ; 44: 174-9$ 
18 Canavan C, West J, Card T. Change in quality of life for patients with irritable bowel syndrome following referral to a gastroenterologist: a cohort study. PLoS One 2015;10:e0139389.

19 Canavan C, West J, Card T. Review article: the economic impact of the irritable bowel syndrome. Aliment Pharmacol Ther 2014;40:1023-34.

20 Pellino G, Sciaudone G, Selvaggi F, et al. Delayed diagnosis is influenced by the clinical pattern of Crohn's disease and affects treatment outcomes and quality of life in the long term: a cross-sectional study of 361 patients in Southern Italy. Eur J Gastroenterol Hepatol 2015;27:175-81.

21 Linedale EC, Chur-Hansen A, Mikocka-Walus A, et al. Uncertain diagnostic language affects further studies, endoscopies, and repeat consultations for patients with functional gastrointestinal disorders. Clin Gastroenterol Hepatol 2016;14:1735-41.

22 Linedale EC, Shahzad MA, Kellie AR, et al. Referrals to a tertiary hospital: a window into clinical management issues in functional gastrointestinal disorders. JGH Open 2017;1:84-91.

23 Australian Institute of Health and Welfare. Australian health expenditure-demographics and diseases: hospital admitted patient expenditure 2004-05 to 2012-13. Health and welfare expenditure series no 59. Cat no. HWE 69. Canberra: Australian Institute of Health and Welfare, 2017.

24 Ryan D, Pelly F, Purcell E. Exploring extended scope of practice in dietetics: a systems approach. Nutr Diet 2017;74:334-40. 